Oleksandr Romanovskyi, Doctor of Economics, Doctor of Education, Professor, Ukrainian-American Concordia University (Kyiv, Ukraine)

Larysa Strashynska, Doctor of Economics, Professor, National University of Food Technologies (Kyiv, Ukraine)

Halyna Bevzo, Ph.D. in Philology, Ukrainian-American Concordia University (Kyiv, Ukraine)

\title{
THE USAGE OF MARKETING APPROACHES IN THE ACTIVITIES MANAGEMENT OF UKRAINIAN HIGHER EDUCATIONAL INSTITUTIONS
}

Abstract: It is noted that during the period of radical socio-political and economic transformations, higher education acts as the main factor determining the level of economic and social development of society. The problem of higher education is outlined, taking into account the demands of the labor market, and also focusing on supporting small and medium enterprises.

It is emphasized that business and higher education exist under the same conditions of dynamic transformation and transformation of society, therefore they have to adapt to real conditions of existence where the best adaptation is certified by non-state higher education institutions that are more flexible and mobile, and it is thanks to it a contradiction between the training of specialists and the demand for them in the labor market is mitigated.

The strategic, long-term and short-term tasks of institutions of higher education, as well as the means of their solution, are defined. It was emphasized that the main priorities are based not on the simple accumulation of knowledge, but on the training of graduates for independent living and the ability to organize their jobs, and therefore there is a need to move from curriculum to educational programs.

The peculiarities of the system of higher education in Ukraine, as well as the advantages of private institutions of higher education in view of the intensification of competition in the market of educational services, are determined. It is substantiated that ensuring the high quality of education in accordance with the requirements of state standards should be carried out taking into account national priorities.

It was emphasized that the development of an effective marketing strategy by educational institutions should be based on a classic strategic planning algorithm taking into account the specifics of educational services. The stages of the strategic marketing planning process of the educational institution are considered and analyzed. The factors that need to be taken into account to ensure the quality of the marketing plan are identified. 
It is emphasized that among the set of marketing mix elements for educational services, the main place belongs to marketing communications, which perform informative, popularization and image functions. It is proved that all marketing communications means of higher education institutions are characterized by their own peculiarities and at the same time are closely interrelated, therefore such integration of marketing communications allows to form a clear, consistent and convincing understanding of the image of the higher education institution and its services.

It is substantiated that for the effective functioning of educational institutions, taking into account the situation not only in the domestic, but also in the foreign market of educational services, the complex use of the means of marketing communications is important and its features are outlined.

It has been established that in the context of the crisis situation in Ukraine, the essential tool of marketing communications are exhibitions, which provide the opportunity for personal contact with future consumers of educational services and interested persons. The essence of the educational exhibition is determined and the advantages of using exhibitions are substantiated.

Keywords: higher education institution; marketing communications; exhibition activity; market of educational services; management of educational institutions; quality of education; state standards.

\section{Problem Statement}

At the current stage of the economic development of Ukraine, the system of higher education increasingly focuses on the labor market, which is established on reliable information concerning market of educational services, demand and supply, prices etc., and requires radical changes in the system of higher education itself. One of the ways of solving this issue is the usage of modern management technologies, among which marketing communications of higher education institutions take the prominent place.

\section{Analysis of recent researches and publications}

A number of leading economists such as H. Armstrong, John Burnet, Philip Kotler, L. Balabanova, A. Balabanyts, O. Brynida, S. Harkavenko, I. Hryshchenko, S. Kolomytseva, V. Kremen, Y. Mayovets, S. Nikolaienko, O. Romanovskyi, K. Savelieva, O. Sardak, S. Stakhurska, S. Tkachuk, V. Kholod, I. Folomkina and many others, dedicated their works to 
the study of problems of the development of higher education in general, as well as peculiarities of marketing of education services. However, despite the thoroughness of conducted researches by the specialists, a number of unresolved issues of the marketing activity of higher educational institutions requires further scientific exploration and research of this particular issue.

\section{The aim of research}

To examine main tasks and priorities of the development of higher education at the present stage, to prove the need of using marketing approaches in the management of the activity of institutions of higher education, to analyze main means of the marketing communications of higher educational institutions and determine priorities of their exploitation.

\section{Research Statement}

Currently, at the times of fundamental socio-political and economic transformations in the world, the problem of correspondence of higher education to the demands of society and time, efficiency of its interactions with science, culture, and education as a whole becomes an issue of a particular importance. In modern conditions, higher education is a key factor which defines the level of economic as well as social development of the society [1, p.15]. It is quite impossible to overestimate the role of higher education for both, economically developed countries and for those, which are poorly developed or are still developing. Whether higher education will have a dominant place in the society and whether people will be contributing to its economic development and humanization depend on the political will and wisdom of the government officials. Globalization of the world economy, modernization of production, broad use of telecommunication facilities and information networks require employees to have a certain level of education. This requirement can be met by a continuous training of the workers and employees, if higher education will follow the labor market [2, p.119].

Higher education is responsible for focusing on the needs of the labor market and to live up to them, to analyze, predict and create new forms of activity and employment, working places, to predict the dynamics of change in the labor force market and to prepare specialists according to the time frames etc.

Taking into consideration that small and medium-sized enterprises are trying to "cure" world economy from an illness of monopoly of the major transnational corporations, to solve an issue of employment of the population and to weaken the dependency of people on monopolies, higher education institutions must support small and medium-sized enterprises, - to examine its essence, foundation of creation and mechanisms of functioning, peculiarities of 
the human factor, it must develop scientifically reasonable concepts, principles, and directions of its further development, to make suggestions to the public authorities as for improvement of legislation in the field of entrepreneurship etc.

It is known that entrepreneurship and higher education are interconnected and enrich each other. Business contributes elements of competition to the higher education, as well as the spirit of entrepreneurship, efforts to work effectively and purposefully. Thus, higher educational institutions are constantly trying to improve their work, to engage the best specialists into the teaching and scientific activities, to apply latest technologies and learning tools. In its turn, higher education enriches entrepreneurship world with new knowledge, results of fundamental and applied scientific researches, humanistic ideas, moral principles and ethics, and contributes to the transformation of the "wild" capitalism to the "civilized" one.

Business and higher educational institution exist under the same conditions of the dynamic changes and transformation of the society. Both entrepreneurship and higher education adapt to the real conditions of existence. Notable progress in the higher education can be noticed in countries where economic development is taking place. On the contrary, higher educational institutions (especially government subordinated) experience difficult times in poorly developed countries and in developing ones. Higher educational institutions of non-state forms of ownership, which are more flexible and mobile, better adapt to any changes and transformations which take place in society. Thank to them, contradictions between training of specialists and their demand in the labor market, softens (because public educational institutions depend more on the economic situation, political, ideological and other factors in Ukraine).

In the conditions of the on-going changing world, higher education is responsible for the solution of the short-term tasks, such as training of specialists for the labor market, as well as long-term - satisfaction of general educational, scientific, and socio-cultural needs of the society.

Unfortunately, instead of pursuing a strategic goal of preparation of the graduates for independent life and training them how to find workplaces, many higher education programs encourage students to only accumulate knowledge [3, p.211]. This is one of the main requirements of a market economy. In addition, statistics indicates a significant increase in scientific data and scientific and technical information of almost all fields of knowledge. For example, the amount of knowledge in computer science doubles every five months. Therefore, it is recommended for higher institutions to shift the emphasis from the broadcasting (retelling and learning) of the material to the ability of independently extracting and using of the knowledge (students must be taught to generate knowledge). 
Every day, when it becomes harder (and sometimes - impossible) to absorb huge amount of information, task number one is to teach person to find all the necessary for him knowledge and to use it effectively in his professional activity. Here we understand the importance of a gradual transition from the teaching programs to the educational programs in its broad sense. According to the education specialists of many countries, during the development of the training programs, priorities should be given to the specializations which are related to the creation and analysis of business (gaming) situations, including the complex ones, which might come up during the practice, prospects and opportunities, which appear in entrepreneurship activity, development of human abilities to act in accordance with situation, and also - to be in touch with the skills of a person, with the need of being responsible citizens of the society and contribute to a further development of the world culture [4, p.27].

Peculiarity of the system of higher education in Ukraine lies in the development of its private sector, opportunity to study abroad, and the expansion of the range of educational services which are provided by the higher education government institutions. This has led to aggravation of the competition for every future student. The main advantage of the private educational institutions is a self-formation of student's internal structure, content of a curricula, professors' time, and salary of professors. Although, state universities as well have the right to provide paid educational services on a basis of a contract. However, the main task of all educational institutions, regardless of their status, is to provide a high quality education in accordance with the requirements of the government standards, taking into account national priorities and intensifying competition in the education market. Consequently, in order to achieve its main tasks, higher education institutions are recommended to use marketing communication tools. As it will ensure simultaneous dissemination and reception of a wide range of versatile information in order to demonstrate benefits of homogeneous services under government or commercial conditions of their provision, quality, and price [5, p.35].

However, communication policy of higher education institutions should be formed taking into account the strategic development that is within frameworks of developed strategy, which involves definition of strategic goals, opportunities and threats, the choice of alternatives and outline for measures for the implementation of the chosen strategy [6, p.23]. We agree with the domestic researchers, who claim that the development of an effective marketing strategy by educational institutions must be based on the classic strategic planning algorithm, however to take into account specifics of the services provided. 


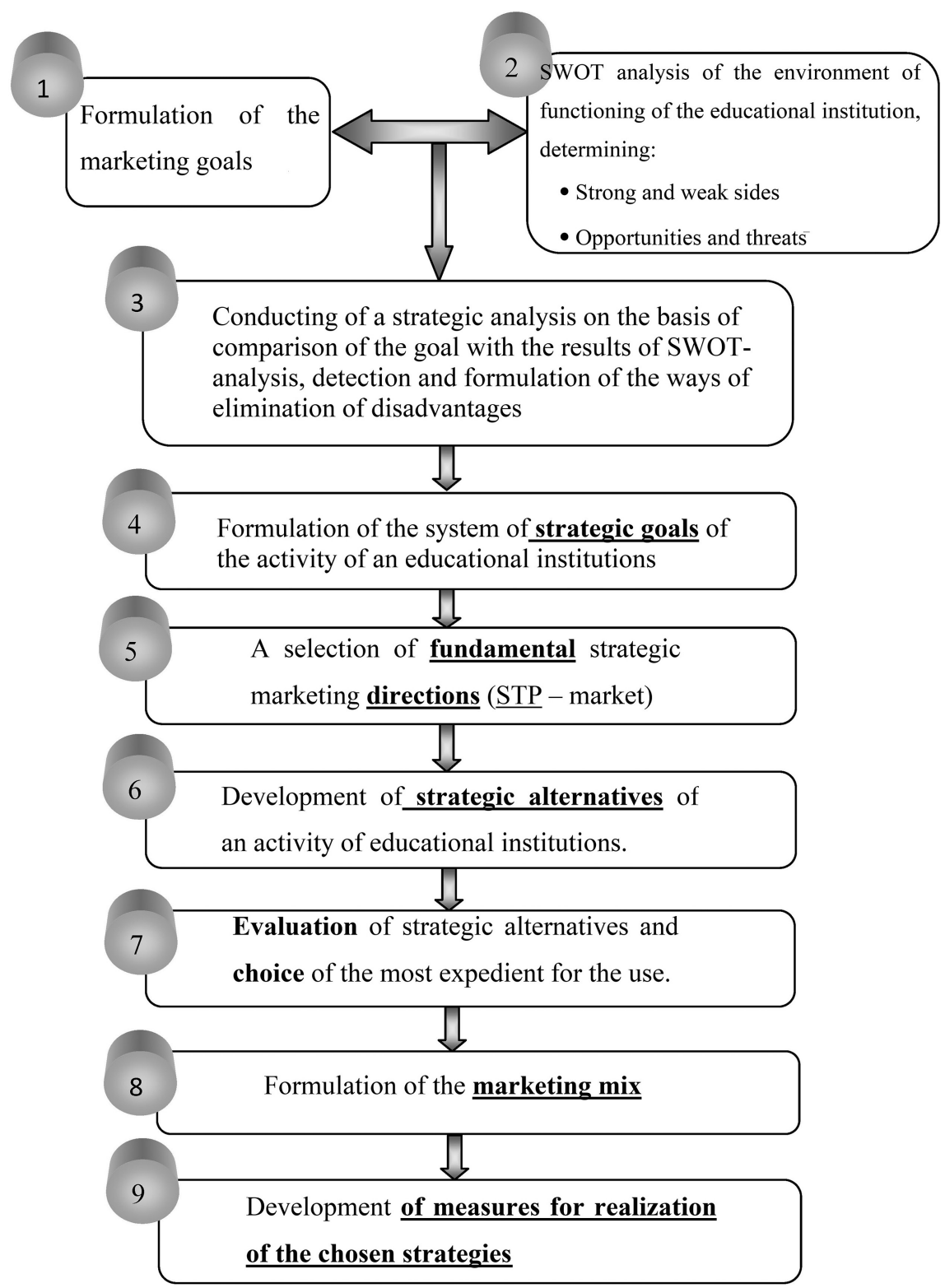

Pic 1. Algorithm of the formation of a marketing strategy of a higher education institutions. $[7$, c. 40$]$.

Process of a strategic marketing planning of an educational institutions consist of the following stages: situational analysis, definition of strategic goals and development of strategic alternatives; formation of a marketing program [8, p.53].

The first stage - situational analysis (SWOT-analysis) includes identifying strong and weak sides of an education institution, its threats and opportunities, as well as the establishment of a direct communication lines between them. Based on a comparison of goals and objectives with the results of the SWOT-analyses, strategic analysis is needed to identify and formulate ways to eliminate any gap.

Second stage - definition of strategic goals involves the creation of a system of strategic goals of educational institution, the formation of an effective strategy of STR-marketing, which 
involves the development of strategic alternatives to the activities of educational institutions, their assessment and the most appropriate choice for implementation.

Third stage - development of a marketing program which involves the formation of the marketing complex, the components combination of which must ensure the effectiveness of the marketing activity of the educational institutions in the future. To develop a complex of marketing in the field of education is proposed in the context of seven elements, suggested by M. Bitner for the service sector: classical (product, price, distribution, promotion) and specific (material status, process, personnel). It is necessary to take into account peculiarities of such service when it comes to shaping the complex of marketing of educational services, as well as specific features of the provided specialty, mentality of future specialists and requirements of the labor market, and not only educational services market.

To ensure the quality of a marketing plan it is necessary to take into account the following points:

- Thoroughly analyze existing advantages and risks;

- Determine the segment of the target market and to choose the best one;

- To choose the most effective tools for implementing the plan;

- To anticipate future steps in case marketing budget will turn out to be bigger or smaller from the suggested one.

$\underline{\text { Main Components }}$

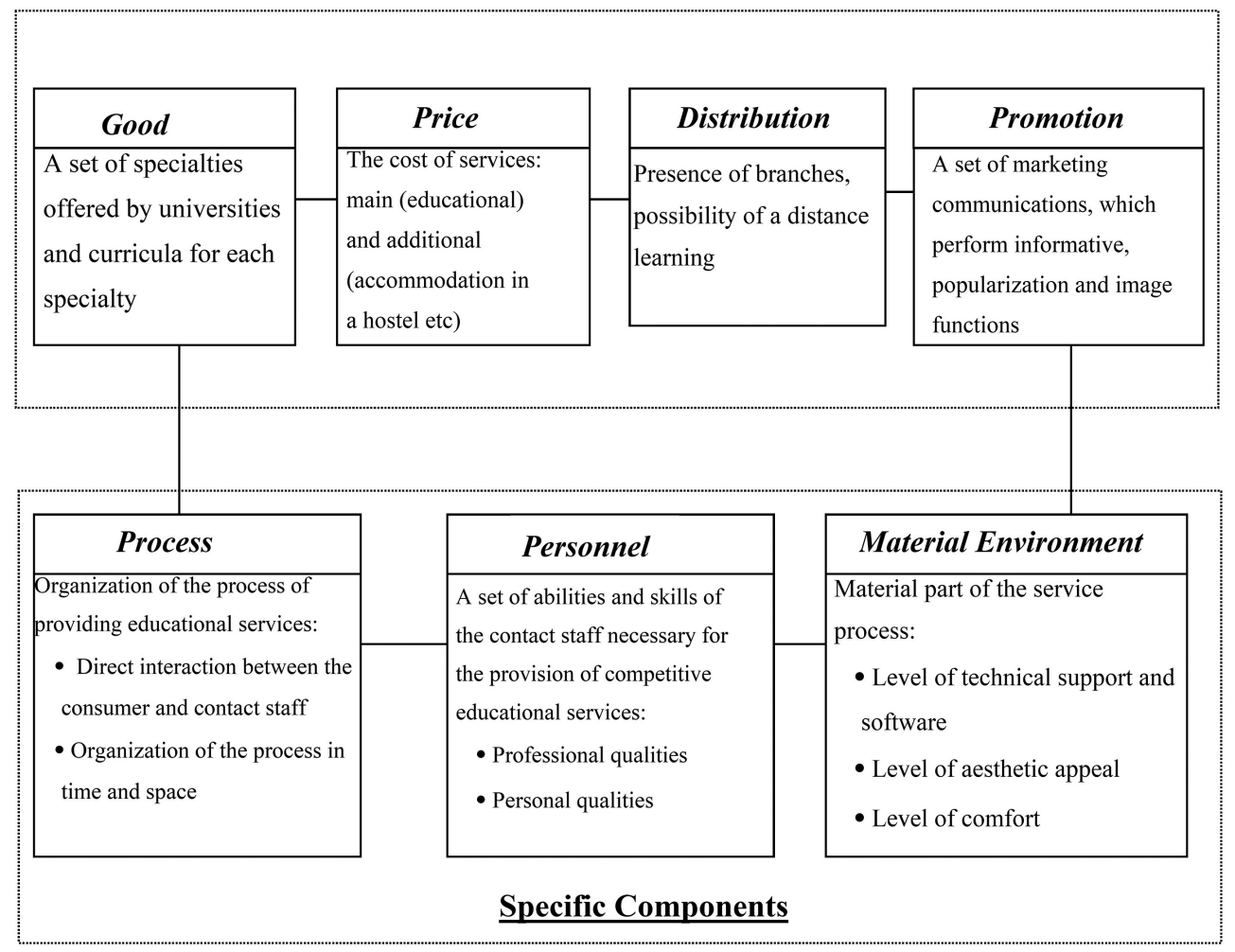

Pic. 2. A set of marketing mix elements for educational services [7, p. 44]. 
Marketing communication take the leading place in the given structure, performing informative, popularization and image functions. According to theoretical approaches of classics of the marketing management, the concept of "marketing communications" should reflect peculiarities of the functioning of all elements of the communication tools, namely: advertisement, exhibitions, personal sales, public relations, direct marketing, and promotion of sales $[9$, p.232; 10, p.56]. All means of marketing communications of the higher educational institutions are characterized by their own features, and at the same time are in a close connection. Each element acts like a source of information for others. Such integration of the marketing communications allows to formulate clear, consistent and convincing understanding of the image of the higher educational institution and services that it provides. For an effective performance of the educational institutions, taking into account not only domestic situation, but foreign market of educational services as well, it is important to use marketing communication tools, with a consideration of the following feature:

- Advertising activity - is of a public figure, encompasses a wide reach of the target audience, multiple appeals, but one-sided direction;

- Exhibition activity - provides direct communication with the target audience, exchange of information, direct contacts of visitors, creates conditions for contacts of professionals in the education sphere, for meetings with representatives of government, from who depend the receiving of the government orders, as well as representatives of small, medium-sized, and large enterprises, the ability to compare homogeneous services with the commercial conditions of their sale, quality, and price;

- Sales promotion is secured by eliminating advantages and features of services, and selling by specific higher educational institutions, it is carried out by the preparatory courses of university, professional orientation work with students of secondary educational, professional and technical educational institutions, to the graduates of higher educational institutions, it is characterized by the possibility of personal contacts;

- Publicity or advocacy of the higher educational institutions and its services shown in a beneficial way due to a high influence on a potential audience through messages in periodical press, news, press, audio and video, special events (presentations, open doors day, anniversary), press releases of university, souvenirs with the symbolism of a particular higher education institutions [5, p.36].

However, in the conditions of a crisis situation in all spheres of human activity in Ukraine, including educational one, financial ability of higher educational institutions not always can 
allow to use all marketing communication tools. As practice shows, exhibitions are the most important marketing communication tool, as they give an opportunity of a direct contact with future consumers of educational services and those who are interested in it. Some processes can be spotted which are taking place during international and domestic exhibitions, in the educational markets of different countries, direction and pace of their development can be seen.

Therefore, we can claim that an educational exhibit - is a marketing communication tool, within which all other marketing communication elements can be implemented. Exhibition events allow to demonstrate scientific and technical achievements of domestic and international higher education institutions. Exhibitions are a reflection of the educational services market; they are considered as an emotional event, which stimulates the decision-making process; they provide and increase the visibility of the educational market; they open a way for higher education institutions towards newly-targeted markets; they allow to establish correspondence between price and quality in comparison to competitors.

Considering an exceptional importance of marketing communications in a structure of the marketing complex for educational institutions, it is advisable to use integrated marketing communications which is explained by the need of reducing the risk of making the wrong decision at the expense of a better knowledge and understanding of the state and dynamics of environmental factors.

\section{Conclusions}

The main prerequisite of Ukrainian integration into European educational environment is a dynamic modernization of a national education system, which is currently in the state of reformation, and the most profound changes took place as a result of globalization processes, in particular the implementation of the Bologna System. Development of educational services in the domestic education market, stipulates the need to intensify marketing activity of the higher education institutions. Increased competition in educational sphere requires the use of the marketing elements from higher education institutions, especially elements of the marketing communications as the necessary tool for managing educational institutions. However, the use of the marketing communications by the higher education institutions requires responsible and a long-term training, and specific knowledge which is related to ensuring the effectiveness of the marketing activity. 


\section{References}

1. Nikolayenko, S.M. (2006). Education in the innovative progress of society. Kyiv: Znannia. 208 p.

2. Zavalko N.A. Problems of education marketing in the aspect of promoting educational services. Omsk University Bulletin. Series “Economy”. 2011. No. 3. P.119-123.

3. Romanovsky, O.O. (2012). The phenomenon of entrepreneurship at world universities: a monograph. Vinnitsa: Nova Knyha. 504 p.

4. Higher Education of Ukraine and the Bologna Process (2007). In V.G. Kremen (Ed.). Ternopil: Navchalna knyha - Bogdan. 384 p.

5. Krakhmalova, N.A., Krakhmalova, T.A. (2014). Marketing in effective management activities of higher educational institutions of Ukraine. Effective economy. Retrieved from http://www.economy.nayka.com.ua/?op=1\&z=3013.

6. Shevchenko D.A. Marketing of educational services / Professional social platform for specialists in advertising and marketing Market-ingpeople [Electronic resource]. Access mode: http: //marpeople.com/articles/253.

7. Tkachuk, S.V., Stakhurskaya, S.A., Stakhursky, V.O. (2018). Marketing of Educational Services: Problems and Prospects. Scientific works of the National University of Food Technologies. Kyiv. Vol. 24. 1. 37-47 https://doi.org/10.24263/2225-2924-2018-24-1-6

8. Krasovskaya, O.Yu. (2009). Models of marketing services in the management system of service organizations. European vector of economic development. 1(6). 52-58.

9. Kotler, F., Keller, K. (2012). Marketing: Management. St. Petersburg: Peter: The World of Books. 479 p.

10. Lavlok K. Marketing services: personnel, technology, strategy, $4^{\text {th }}$ ed. - M .: Publishing House «Williams», 2005. 108 p. 